\title{
As Comunidades Rurais da Gália Tardo-Romana: consumo, ascensão social e crise
}

\section{The rural communities of Lat Roman Gaul: consumption, social ascension and crisis}

\section{Las comunidades rurales de la Galia tardorromana: consumo, ascenso social y crisis}

\section{Uiran Gebara da Silva}

uirangs@hotmail.com

Universidade Federal Rural de Pernambuco.

Departamento de História, Brasil

Recepção: 30 Janeiro 2020

Aprovação: 16 Julho 2020

Publicação: 01 Março 2021

Cita sugerida: Silva, U. G. da (2021). As Comunidades Rurais da Gália Tardo-Romana: consumo, ascensão social e crise. Sociedades Precapitalistas, 11, e055. https://doi.org/10.24215/22505121e055
Resumo: Este artigo tem como problema central a compreensão dos padrões de vida das comunidades rurais do Norte da Gália tardo-romana. Inicialmente apresenta uma reflexão teórica sobre as definições conceituais utilizadas e o impacto da mudança de paradigma no estudo da sociedade e economia tardo-romana (do "Declínio e Queda" para o da "Continuidade da Romanitas") sobre o estudo das comunidades rurais. Em seguida problematiza a cultura material das regiōes rurais em termos de fenômenos visíveis e invisíveis e, a seguir, analisa dados oriundos de estabelecimentos rurais observando e propondo alguns modelos de interpretação das relações sociais, econômicas e culturais em algumas regiốes da Gália romana. O artigo conclui propondo a elaboração de modelos e categorias que, a partir de uma compreensão mais fina das comunidades rurais, possam representar também de forma mais complexa suas formas de organização comunitária.

Palavras-chave: Comunidades Rurais, Campesinato, Gália, Império Romano, Estabelecimentos rurais.

Abstract: This article focuses on understanding the living standards of rural communities in northern late Roman Gaul. Initially it presents a theoretical reflection on the conceptual definitions it employs and on the impact of the paradigm shift in the studies of late Roman society and economy (from the "Decline and Fall" to the "Continuity of the Romanitas") on the study of rural communities. It then problematizes the material culture of rural areas in terms of visible and invisible phenomena and then analyzes data from rural establishments by observing and proposing some interpretation models for the social, economic and cultural relations in Roman Gaul. The article concludes by proposing the elaboration of models and categories that, through a finer understanding of rural communities, can also more complexly represent their forms of community organization.

Keywords: Rural Communities, Peasantry, Gaul, Roman Empire, Rural Establishments.

Resumen: Este artículo tiene como problema central la comprensión del nivel de vida de las comunidades rurales del norte de la Galia tardorromana. Inicialmente, presenta una reflexión 
teórica sobre las definiciones conceptuales empleadas y el impacto del cambio de paradigma en el estudio de la sociedad y de la economía tardorromana, desde de la idea de "Decadencia y Caída" hacia a la de "Continuidad de la Romanitas", en las investigaciones acerca de las comunidades rurales. A continuación, problematiza la cultura material de las regiones rurales en términos de fenómenos visibles e invisibles, y a seguir analiza los datos de los asentamientos rurales, observando y proponiendo modelos de interpretación de las relaciones sociales, económicas y culturales en algunas regiones de la Galia. El artículo concluye proponiendo el desarrollo de modelos y categorías que, basados en una comprensión más sofisticada de las comunidades rurales, pueden representar, también de una manera más compleja, sus formas de organización comunitaria.

Palabras clave: Comunidades rurales, Campesinos, Galia, Imperio Romano, Asentamientos rurales.

\section{Introdução}

O estudo ${ }^{1}$ aqui apresentado ${ }^{2}$, que tem como objeto de análise a compreensão dos padrões de vida das comunidades rurais do Norte da Gália tardo-romana, toma como ponto de partida as inúmeras mudanças recentes que aconteceram na Historiografia e nos estudos de Arqueologia sobre os habitantes das regiões rurais do Império Romano e que tiveram importantes repercussões no estudo da Gália rural. Ao longo dos séculos XIX e XX, os estudiosos da Gália romana produziram uma imagem que sempre tendeu a subvalorizar a existência das comunidades no Norte da Gália, dando uma enorme centralidade para grandes propriedades rurais e seus proprietários, considerados os únicos elementos observáveis no campo galo-romano. A partir do final do século XX, porém, as mudanças na produção acadêmica passaram a possibilitar o desenvolvimento de novas perspectivas sobre as áreas rurais da Gália, assim como sobre as comunidades rurais ali localizadas. Um segundo tema que é explorado neste estudo são os problemas teóricos e metodológicos relacionados aos limites impostos pela documentação material e textual no que diz respeito às representações que historiadores e arqueólogos fazem das comunidades rurais tardo-romanas.

Para dar conta desses dois temas, inicialmente apresento uma reflexão teórica sobre as definições conceituais utilizadas e o impacto que a mudança de paradigma no estudo da sociedade e economia tardo-romana tiveram sobre o estudo das comunidades rurais. Em seguida reflito sobre as dificuldades oferecidas a qualquer tentativa de reconstrução das comunidades rurais galo-romanas a partir de um mapeamento de assentamentos rurais do Norte da Gália entre os séculos III e V d.C. Nesta etapa busco primeiro problematizar esse acervo de cultura material em termos de fenômenos visíveis e invisíveis e, em seguida, analiso os dados nele observado e proponho alguns modelos de interpretação das relações sociais, econômicas e culturais dessas regiões da Gália romana. Concluo com uma reflexão sobre essas dimensões visíveis e invisíveis de tais comunidades na cultura material, apontando para a necessidade de elaboração de modelos e categorias menos binários e mais complexos e dialéticos do que se postulava na historiografia do século XX. 


\section{Comunidades Rurais Tardo-Romanas - problemas teóricos}

O propósito desta seção é apresentar algumas definições conceituais e descrever o impacto do paradigma de continuidade econômica e social da Romanitas $^{3}$ sobre o estudo das comunidades rurais galo-romanas.

O estudo das comunidades rurais da Gália tardo-romana é profundamente determinado pelos limites impostos pela documentação empírica e, consequentemente, muito do que se pode dizer ou não sobre essas comunidades acaba dependendo das balizas teóricas (e comparativas) utilizadas na pesquisa, o que faz com que um exame das definiçóes conceituais e dos pressupostos historiográficos seja particularmente pertinente. Um dos desdobramentos dessa problemática é a crítica ao que chamo de "modelo de patronato rural de longa duração" ao qual retornarei no curso deste artigo.

\section{a. Comunidades Rurais}

As dificuldades da noção de comunidades rurais podem ser analisadas por meio da consideração em separado dos dois termos que a compõem. "Comunidade" como conceito automaticamente remete a seu par "sociedade", e a oposição é geralmente baseada na ideia de um aumento no grau de complexidade indo de uma (comunidade) à outra (sociedade). Por trás dessa oposição estão estudos e ensaios já clássicos, como os de Tönies que à primeira associa a constituição valores coletivos e à segunda valores individuais, ou de Durkheim, que assentam essa mesma dicotomia sobre o processo de divisão social do trabalho e na oposição entre solidariedade mecânica e orgânica ${ }^{4}$. Eu penso que mais importante do que ignorar ou me contrapor ponto a ponto à essa corrente de estudos, seja interessante pensar essas dicotomias em outros termos. Para escapar da ideia de que as comunidades sejam menos complexas que as sociedades - pois são complexas em outros termos - recorro à noção de mediações ${ }^{5}$. Numa comunidade, as relações entre os indivíduos ou as unidades domésticas (households) e o todo da coletividade social são menos mediadas, do que naquilo que a tradição sociológica denomina "sociedades". Isso nos leva a um problema de escala e ao reconhecimento de que o conceito de comunidade está subsumido ao de sociedade, não sendo simplesmente uma noção que representa etapas menos desenvolvidas, mas um componente daquilo que o segundo termo representa. Isso, claro tem grandes implicações para o seu uso no contexto tardo-romano.

"Rural" também tem o seu oposto forte em "urbano". Assim, o rural é geralmente definido, na literatura especializada, por meio de características negativas, como aquilo que não possui as características do meio citadino, urbanizado. Para evitar a repetição de um debate sem $\mathrm{fim}^{6}$, proponho que se recorra a uma visão positivada do rural. Isto é, as comunidades rurais são aquelas cuja existência se dá num contexto imediato de atividades agrícolas ou pastoris de produção, o que permite ao pesquisador estabelecer definições substantivas do rural. Tal procedimento poderia valer até mesmo para sociedades modernas, que alteraram profundamente a dinâmica produtiva agrária, pois nelas as atividades rurais prosseguem produzindo organização social, costumes, símbolos e ideologias distintos dos urbanos. 


\section{b. Campesinato}

Outra noção que demanda algumas considerações é a de Campesinato. Por causa das origens europeias do termo campesinato, muitas vezes critica-se o seu emprego em outros recortes geográficos e culturais (Bernstein \& Byres, 2001). Da mesma forma, sua conexão original com as configurações rurais europeias especificamente medievais e modernas levanta críticas ao seu emprego para o contexto da Antiguidade - mediterrânica ou oriental (Cardoso, 2002). Há aqui também uma tensão entre diferentes determinações históricas e culturais que coloca novamente oposições binárias pouco frutíferas, ou que levam à um nominalismo que atravanca os estudos comparativos e não lida com as determinações sociais comuns que estão sendo nomeadas e representadas. 7 Concentro-me, inspirado na reelaboração dos modelos de Alexader Chayanov proposta recentemente por Jan Douwe Van der Ploeg (2008), nos elementos constitutivos do conceito de campesinato. Desta forma, a noção de campesinato, quando empregada como ferramenta heurística (e não com camisa de força), permite pensar as dimensões gerais e particulares das condições sociais, da organização política e das elaborações culturais associadas às comunidades rurais, assim como permite entrever sua contribuição para uma compreensão transhistórica (e não a-históricas) das relações sociais rurais.

O primeiro destes elementos constitutivos é a família entendida como unidade doméstica produtiva, consumidora, social e cultural. Esta unidade, digamos, existencial, é também mediadora entre os indivíduos e a coletividade superior, seja ela a comunidade rural, seja ela uma forma política mais ampla. A esta unidade se articulam as configurações variadas do trabalho rural, que em sociedades pré-capitalistas são geralmente delineadas em torno de um espectro de estatutos sociais (livre, semi-livre, escravo, etc.), que organizam num plano político e ideológico o controle do trabalho dos membros das comunidades rurais. Este último determinante, por sua vez coloca o problema do trabalho compulsório nessas comunidades rurais: por um lado, o emprego de escravos pelos grandes proprietários ou pelos pequenos e suas consequências, pelo outro, a questão de fundo na historiografia sobre o colonato e patronato rural tardoromanos: o quão compulsório era o trabalho do camponês romano? No que diz respeito aos habitantes das áreas rurais do império romano tardio, muitas das características constitutivas do conceito de campesinato podem ser ali identificadas (Grey, 2011; Ste. Croix, 1998; Wickham, 2005).

\section{c. Paradigmas}

O último tema que trabalharei nesta seção é uma breve consideração sobre o impacto da mudança de paradigmas historiográficos sobre a História Agrária do Império Romano tardio. $\mathrm{O}$ paradigma historiográfico anteriormente dominante sobre a sociedade romana entre os séculos III e V apresentava o Império Romano como uma totalidade social em crise ou em decadência. As dimensões agrárias e rurais de tal decadência eram articuladas a partir de concepções que apresentavam um processo profundo de desarticulação do Império, em alguns casos, já a partir do século II, e que tendia a projetar já sobre o período tardio a perspectiva de uma 
proto-feudalização das relações sociais. A primeira era a teoria da naturalização da economia, com a regressão das redes comerciais, simplificação da produção e retorno à autossuficiência (Lot, 1989; Weber, 1983). A outra era visão de crise da produção escravista em grande escala, que tinha como corolário o fortalecimento do patronato rural e o surgimento da legislação do colonato que aprisionaria os camponeses livres nas propriedades rurais (Anderson, 2000; De Coulanges, 1894; Giardina, 2007; Ste. Croix, 1998; Weber, 1983). A partir dos anos 1970, o paradigma historiográfico sobre o período começou a se transformar e, com a consolidação do campo da Antiguidade Tardia, os estudiosos, influenciados em parte pela virada linguística (Bowersock, 2001; Brown, 1971; Cameron, 1993), em parte pela explosão de estudos de arqueologia romana (Bowden et al., 2004; Leveau, 2007; Lewit, 1991), passaram a apresentar um Império Romano tardio diferente. Quando se tomava como foco as províncias e não o centro italiano, o que se via nelas era um crescimento econômico comparável àquele dos séculos I a.C. a II d.C. Neste contexto, passou-se a literalmente usar conceitos como "crescimento econômico" e "desenvolvimento", a reconhecer o desenvolvimento, antes ignorado de redes comerciais regionais e locais nas províncias, assim como a examinar indícios escritos e materiais de formas muito criativas de organização da produção rural, como o emprego de diversidade de portfólio produtivo e de monetarização das áreas rurais que iam na contramão da naturalização da economia antes propalada (Banaji, 2007, 2010; Bowman \& Wilson, 2013b; Erdkamp et al., 2015; Halstead, 1987; Horden \& Purcell, 2000). É em tal contexto que o estudo das comunidades rurais da Gália tardo-romana deve se inserir.

\section{Assentamentos Rurais - Fenômenos Visíveis e Invisíveis}

Pretendo no que se segue abordar o processo recente de desconstrução das representações historiográficas das comunidades agrárias da Gália romana produzidas em meados do século XX. Os dados empíricos e interpretações mais recentes tendem a questionar muitos dos conceitos que sustentavam a visão das comunidades rurais na Gália como miseráveis, passivas e totalmente subordinadas às elites locais. Em seguida apresento a análise feita a partir de um mapeamento restrito de assentamentos rurais entre os séculos III e V d.C.

As representações das regiões rurais da Gália romana produzidas nos séculos XIX e XX costumavam delinear os habitantes das regiões rurais fundamentalmente por meio de um "modelo de patronato rural de longa duração”. Essa historiografia, incrivelmente homogênea, propunha para a Gália do Império inicial uma configuração das relações de trabalho rural com pouca escravidão (diferentemente da configuração sugerida para outras áreas do Império) e a dominação clientelística dos trabalhadores rurais, arrendatários ou pequenos proprietários pelos grandes proprietários rurais (mesmo que a documentação para tais relações clientelísticas fosse altamente discutível). No período tardio, esse quadro seria aprofundado por dois fatores: o colonato e o patronato rural. O primeiro deles seria uma forma de vinculação permanente dos camponeses arrendatários à terra, organizada pelo Governo imperial, e o segundo, por sua vez, uma formalização legal do quadro anterior de dominação pessoal. Assim, seguindo a perspectiva da historiografia de meados do século XX, se em 
outras regiões do Império (como a Itália), o período tardio seria visto como uma época de piora das condições dos agricultores livres, na Gália a historiografia apresentava a continuidade de uma situação de dependência permanente. ${ }^{8}$

Como já mencionado, entre os anos 1970 e 1990, houve uma intensificação dos trabalhos de arqueologia rural romana. A assim chamada Nova Arqueologia Rural compreendeu o emprego sistemático de Arqueologia Aérea, da Prospecção e da Arqueologia da Paisagem (Chavarría \& Lewit, 2004; Dyson, 2003). Neste contexto, escavações e prospecções foram feitas ao Sul e ao Norte da França. Contudo, a força do paradigma anterior de compreensão do campo era tamanha que, mesmo com os indícios de que ele não se sustentava sendo progressivamente encontrados pela Arqueologia, estes eram logo subsumidos e interpretados de forma a se encaixar no modelo prevalecente. Quando as investigações de Roger Agache no Norte da Gália e, particularmente na Picardia, demonstraram a ocupação intensa da região, não só por villae, mas também por pequenos assentamentos espalhados pela região que muitas vezes reocupavam e repartiam o espaço de velhas grandes propriedades (Agache, 1970), iniciouse um debate entre ele e Edith Wightman (Agache, 1978; Wightman, 1978). A força da argumentação de Wightman e da inércia do modelo de patronato rural convenceram Agache a diminuir em suas interpretações finais o peso que dava à presença de escravidão rural nas villae. E assim passou a considerar aquela reocupação tardia como nucleações proto-medievais de colonos, comandadas pelos grandes proprietários ausentes, agora vivendo em novos núcleos urbanos, resultado de um processo amplo de vici sendo tornados civitates (Rorison, 2001). O patronato rural de longa duração permanecia intocado. ${ }^{9}$ Contudo, com o prosseguimento da investigação arqueológica rural décadas seguintes, revelou-se que a visão de Wightman, que extrapolava a situação específica de miséria da Gallia Belgica para todo o Norte, não é sustentada pela evidência empírica mais recente (Ouzoulias \& Van Ossel, 2000).

Uma última consideração importante diz respeito às formas de análise dos dados produzidos pela investigação arqueológica recente. Em primeiro lugar, parto de um conjunto de orientações propostas por Paul Van Ossel, que acredito sejam bons critérios para a investigação de classes subalternas a partir da cultura material: 1) observar os sistemas locais de organização dos assentamentos e a distribuição dos objetos tem prioridade sobre as comparações com períodos anteriores e posteriores; 2) evitar generalizaçóes baseadas apenas na mudança de tipos de materiais de construção e arquitetura; 3) quaisquer relações entre a cultura material e "identidade étnica" (romano e não romano) estão subordinadas a determinações derivadas de padrões regionais de comportamento e diferenciação de classes; 4) a invisibilidade das relações de propriedade no registro material salvo raríssimas exceções (Van Ossel, 2006). Essa maneira de olhar para os vestígios materiais dialoga com um desenvolvimento recente da Arqueologia do Consumo, que busca articular os dados recolhidos em escavação e prospecção - mais prospecção do que escavação.

Estas orientações são uma resposta às interpretações anteriormente dominantes. O quadro social proposto nelas para o Norte da Gália era composto por processos de 1) queda e persistência da ocupação; 2) mudança no padrão de assentamento indo do disperso para o nucleado; 3) empobrecimento entre as classes já pobres e, por fim, 4) a desintegração social. Em meio a esse quadro 
ela apresentava 5) os habitantes rurais da Gália setentrional cada vez mais subordinados aos poderes dos potentados locais, aos quais a legislação sobre o colonato teria auxiliado a fortalecer ainda mais as relações de dependência pessoal.

Adicionalmente, uma vez que o objetivo aqui é desvendar os padróes de vida das comunidades rurais, recorro a alguns conceitos derivados da chamada Arqueologia do Consumo (Millet, 1991). Formulada como uma resposta metodológica à associação imediata de dados arqueológicos à resultados de aumento ou diminuição populacional, a Arqueologia do Consumo propõe que todos os objetos encontrados em uma área investigada devem ser antes pensados como representativos das mudanças dos padrões e hábitos de consumo, antes de serem traduzidos para informações relativos à população local. Neste sentido, mais recentemente, foi proposto que tais hábitos e padrões de consumo inferidos a partir dos achados arqueológicos também podem apontar para mudanças nos níveis e padrões de vida dos habitantes de uma região estudada (Alcock, 1996; Millet, 2000; Ouzoulias \& Van Ossel, 2009; Ward-Perkins, 2005) e, por conseguinte, também podem ser usados para pensar a evolução das condições de vida das classes subalternas urbanas ou rurais (Dossey, 2010; Wickham, 2005). Tal abordagem depende de um conjunto de pressupostos interpretativos sobre a natureza dos processos de produção e distribuição dos objetos encontrados em campo. A partir da complexidade dos sistemas culturais e das formas de produção que se infere dos objetos encontrados, tal abordagem tende a produzir hierarquias sociais e econômicas entre as áreas analisadas. A maior ou menor complexidade do sistema cultural ou produtivo se baseia 1) na maior ou menor divisão social e regional do trabalho, 2) no maior ou menor desenvolvimento técnico e 3) na maior ou menor complexidade distributiva - incluindo a consolidação de sistemas comerciais locais ou regionais (Erdkamp, 2015; Ward-Perkins, 2005; Wickham, 2005). O risco - real e verificável em parte da bibliografia - é interpretar essas gradações, primeiro, como processos lineares de evolução social e, segundo, como expressões de relações sociais modernas e capitalistas (Bowman \& Wilson, 2013a; Scheidel et al., 2007; Zuiderhoek, 2015). Não é o que se pretende fazer aqui. $\mathrm{O}$ estudo que apresento neste artigo busca usar as referências teóricas e metodológicas da Arqueologia do Consumo (Alcock, 2000; Aston \& Rowley, 1974; Banning, 2002; Barker, 1991; Bowman \& Wilson, 2013a; Chouquer \& Favory, 1991; David \& Thomas, 2008; Feinmann, 2015; Ferdière, 1988a, 1988b; Ouzoulias, 2006; Ouzoulias \& Van Ossel, 2000) como forma de pensar os objetos encontrados e as hierarquias sociais que se pode inferir deles e dos assentamentos rurais de forma a apreender os diferentes padrões de vida rural no Norte da Gália. Acredito que a tentação modernizante criada pelo volume recente de dados empíricos pode ser mitigada numa atitude mais crítica nos momentos posteriores de interpretação.

Por fim, seguindo a proposta apresentada por Van Ossel (2006), uso a noção de "empobrecimento" como conceito organizador da análise inicial dos conjuntos de objetos encontrados em um dado sítio ou assentamento. Assim, por um lado essa noção remete a um exercício comparativo dos dados locais com os diferentes e múltiplos níveis de riqueza que se pode encontrar localmente, regionalmente ou mesmo inter-regionalmente, i.e. no Mediterrâneo como um todo. Por outro, nos oferece um filtro interpretativo que serve de mediação entre as práticas de 
uso e consumo locais - visíveis na cultura material - e outras interpretações das configurações sociais que ali estão invisíveis.

O emprego da diferenciação heurística entre fenômenos visíveis e invisíveis na documentação revela os problemas da visão de Wightman. Por um lado, o quinto item, as relações de patronato, colonato e propriedade da terra, que Wightman apresentava como centrais em seu modelo são invisíveis na documentação material. Adicionalmente, tais relações baseiam-se em descrições das comunidades rurais feitas por Salviano de Marselha ou Sidônio Apolinário, que a literatura especializada hoje tende a associar especificamente às condiçóes da Gália meridional, quando não as contesta como exageradas e caricaturais (Goffart, 2008; Grey, 2011; Lambert, 2002). Por outro lado, os primeiros quatro itens fundamentando as teorias de Wightman se encontram entre os fenômenos visíveis: padrões de assentamento e de ocupação nas regióes rurais, assim como sinais de enriquecimento, empobrecimento, e de integração ou desintegração das redes de sociabilidade entre as comunidades rurais e comunidades mais amplas. Porém, o quadro apresentado pelos estudos recentes sobre a Gália setentrional tardo-romana não corresponde àquele elaborado por Edith Wightman.

No que se segue, a metodologia utilizada para a seleção dos assentamentos se baseou em uma característica singular dos estudos sobre os assentamentos rurais na Gália romana e medieval: o foco dos investigadores no que eles denominam "estabelecimentos rurais" (Ouzoulias et al., 2001; Peytremann, 2003; Van Ossel, 1992). As investigações, embora recorram bastante às práticas de prospecção e de observação da paisagem, evitam apoiar-se no mapeamento de sítios rurais apenas a partir dos achados em cerâmica, concentrando-se nas áreas com claros sinais de construção de habitações e de assentamento humano. Sendo, neste sentido, muito mais conservadores do que a Arqueologia rural britânica, a prospecção tem um papel secundário no que diz respeito ao assentamento ou população, mas primário no que diz respeito às práticas sociais das comunidades rurais no período tardio (Daveau, 1997; Davies \& Astill, 1994; Lenz, 2001; Ouzoulias \& Van Ossel, 2000, 2001).

\section{a. Gália Lugdunense}

Apresento agora uma análise dos dados conseguidos por meio do mapeamento que realizei de assentamentos rurais entre os séculos III e $\mathrm{V}$ d.C., de forma a ilustrar as mudanças acima discutidas. Com tal análise, busco também problematizar esse acervo de cultura material e os indícios por ele fornecidos das comunidades rurais em termos de fenômenos visíveis e invisíveis. $\mathrm{O}$ recorte espacial desse mapeamento como um todo engloba a região das províncias tardoromanas correspondentes à província alto-imperial Lugdunensis, depois dividida nas províncias tardo-imperiais Lugdunenses I, II, III e IV (ou Senonia). Tal recorte espacial buscava operar entre demandas de um estudo regional (o Norte da Gália) e as de um estudo local (os assentamentos em uma região ou départament francês moderno). Aqui apresento uma análise com teor mais quantitativo dos dados extraídos dos assentamentos analisados. Contudo, duas considerações preliminares são importantes. Em primeiro lugar, é necessário ter em mente o quanto o qualitativo na forma de conceitos e operaçóes de modelagem atuam por trás do tratamento quantitativo dos dados (Bowman \& 
Wilson, 2013a; Goodchild, 2013). Em segundo lugar, há um desequilíbrio na amostragem da distribuição de assentamentos analisados entre as quatro regiões que compõem a Lugdunense como um todo. Assim, a lista de assentamentos rurais apresenta 31 (trinta e um) assentamentos referentes à Lugdunense IV, 18 (dezoito) referentes à Lugdunense III, 3 (três) referentes à Lugdunense II e 8 (oito) referentes à Lugdunense I. Esse desequilíbrio é resultado da dificuldade de acesso a artigos ou relatórios de investigação sobre os assentamentos e sítios em certas regiões da Gália. ${ }^{10} \mathrm{O}$ maior impacto desse desequilíbrio se dá sobre a análise isolada dos dados quantitativos da Lugdunense II, cuja amostra de 3 assentamentos torna impossível qualquer conclusão a seu respeito. Dessa forma, embora a investigação cujos resultados parciais apresento aqui tenha se preocupado com a modelagem dos dados oriundos das quatro províncias lugdunenses, o que se apresenta aqui são apenas o tratamento dos dados referentes à Lugdunense como um todo, o que adicionalmente atenua, no conjunto de 60 assentamentos, o desequilíbrio associado à Lugdunense III.

\section{a1. Queda e persistência da ocupação}

Aqui apresento alguns dos resultados relativos à queda ou a persistência da ocupação das regiões. $O$ tratamento dos dados e a análise se basearam na observação da ocupação humana dos assentamentos de acordo com três categorias: Ocupação, Interrupção e Vazio. Ocupação significa que o assentamento está ocupado sem interrupção alguma ao longo de todo o período de um século. Interrupção significa que o assentamento passou por algum processo de desocupação, permanente ou temporária no período de um século. Vazio significa que o assentamento no período observado já estava desocupado há mais de um século. Muito embora os dados de ocupação e abandono tabulados se estendam do período pré-romano até o século 10 d.C., a análise se concentrou nos períodos tardo-antigos, isto é, entre os séculos III e VI que eram o foco da pesquisa. No item al desta seção, a análise observa apenas o aumento ou queda nos níveis de ocupação, sem considerar a sua forma - que pode variar bastante - nos itens a3 e a4 desta seção, será possível verificar que há importantes mudanças na forma dessa ocupação.

O Quadro 1mostra os números totais da lista de assentamentos na Lugdunense entre o II e o VI séculos. O padrão que se encontra é interessante. No século III, apesar de sua má fama como um período de crise, o número de interrupções é considerável, mas parte dele é compensado por novas ocupações. Uma queda suave da ocupação entre o III e o IV, expressa no aumento de interrupções, mas que são acompanhadas por reocupações e pela redução do número de assentamentos vazios no mesmo período. Aqui temos uma permanência de 39 ocupações entre esses dois séculos, menor em comparação ao total de 45 ocupados no II, o pico de ocupação, mas quase o dobro do que se encontra no V. No século $\mathrm{V}$ tem-se então um aumento intenso das interrupções de ocupação dos assentamentos que não são compensadas no VI. Temos no $\mathrm{V}$ o número mais baixo de ocupação, apenas 21 dos totais 60 assentamentos da amostra para a Lugdunense ocupados. No século VI, repetindo o padrão encontrado regionalmente, muitas reocupações fazem com que quase se retorne ao número de ocupações do século IV: 34 . O número de assentamentos vazios, 
isto é, não ocupados por dois séculos em sequência, contudo sobe drasticamente, o que sugere que a queda sofrida no $\mathrm{V}$ teve um impacto maior do que a que ocorre no III.

\begin{tabular}{|c|c|c|c|}
\hline \multicolumn{4}{|c|}{ Quadro 1 - Lugdunense total } \\
\hline Total & Interrupção & Ocupação & Vazio \\
\hline II & 6 & 45 & 9 \\
\hline III & 10 & 39 & 11 \\
\hline IV & 15 & 39 & 6 \\
\hline V & 30 & 21 & 9 \\
\hline VI & 2 & 34 & 24 \\
\hline
\end{tabular}

\section{a2. Padrão de assentamento - nucleado versus disperso}

A natureza indireta do meu trabalho de coleta de estudos arqueológicos e a forma de tratamento realizado nos dados obtidos dos assentamentos rurais examinados não me permitiu lidar diretamente com esta dimensão das teorias tradicionais sobre o campo da Gália tardo-romana. Isso pode ser feito por meio de uma observação mais localizada, e indireta, com recurso ao estudo de Isabelle Daveau sobre a Île-de-France.

Tomo aqui uma representação gráfica do espaço ocupado (Imagem 1) elaborada por Daveau que apresenta os padrões de assentamento na área de Paysde-France. Ao contrário do modelo prevalecente no século XX, o que se pode identificar é a manutenção do padrão disperso de ocupação por todo o período tardo-romano, que como pudemos ver no quadro anterior, apresentou uma alta incidência de criação de novos sítios, apresentando certa mobilidade da ocupação mas ainda assim, uma enorme permanência nessa mesma região sem a nucleação esperada pela hipótese de Wightman.

Imagem 1 - Continuidade de habitação dispersa - sítios em Pays de France (Daveau, I. 1997)

\begin{tabular}{|c|c|c|c|} 
Total & Interrupção & Ocupação & Vazio \\
\hline II & 6 & 45 & 9 \\
\hline III & 10 & 39 & 11 \\
\hline IV & 15 & 39 & 6 \\
\hline V & 30 & 21 & 9 \\
\hline VI & 2 & 34 & 24 \\
\hline
\end{tabular}

\section{a3. Empobrecimento?}

A dimensão aqui analisada lida com a piora ou melhora de condições de vida dos habitantes das zonas rurais das quatro províncias Lugdunenses. Como mencionado anteriormente, esta dimensão de análise demanda muitos cuidados, dado o peso que a visão de empobrecimento e piora do nível de vida dos 
camponeses tinha nas interpretações mais recorrentes da Gália tardo-romana ao longo do século XX.

Partindo das consideraçóes acima esboçadas sobre a Arqueologia do Consumo e o foco da produção recente nos estabelecimentos rurais, pretendo apresentar aqui algumas interpretações sobre a variação dos padrões de vida dos habitantes da região analisada. Para isso, estabeleci algumas categorias com as quais busquei classificar os objetos e formas de estabelecimentos rurais retirados dos assentamentos coletados de forma a construir possíveis modelos que descrevam o desenvolvimento dos padrões de vida nas quatro áreas analisadas.

Nesta seção, há dois momentos de análise, que correspondem a dois conjuntos diferentes de dados. $\mathrm{O}$ primeiro conjunto se refere ao que classifiquei como "Aspectos da Construção dos Estabelecimentos Rurais", ou apenas "Aspectos", que correspondem às características arquitetônicas ou decorativas dos estabelecimentos. Aqui são incluídos de forma geral, as técnicas e material de produção dos estabelecimentos, tanto no que diz respeito aos elementos estruturais, quanto aos elementos ligados à decoração. Também se incluem aqui as categorias que dizem respeito ao tamanho dos estabelecimentos ou número de estabelecimentos encontrados em conjunto (um problema incluído nesta etapa da análise, para o qual, porém, a amostra recolhida não me pareceu suficiente para extrapolar em termos de nucleação ou dispersão dos assentamentos). $\mathrm{O}$ primeiro momento de análise partiu dos Aspectos e buscou apresentar a proporção relativa das diferentes formas de construção, primeiro no período Imperial inicial, e em seguida no período tardio na Gália Lugdunense. Segue abaixo uma breve descrição das categorias aqui utilizadas.

$\mathrm{V}$ ou Villa significa que o estabelecimento possui um tamanho equivalente ou ao menos próximo ao tamanho do que seria considerado uma grande propriedade no Sul da Gália ou na Itália (Becker \& Terrenato, 2012; Carandini, 1985; Chouquer \& Favory, 1991), sendo composto de uma enorme casa com muitos quartos e, geralmente, outros edifícios anexos, formando um complexo cujas dimensões transcendem (geralmente em muito) os $100 \mathrm{~m} 2$. M ou Médio corresponde a estabelecimentos de tamanho médio, usualmente isolados, muito menores do que os estabelecimentos do item anterior: variando entre $20 \mathrm{~m} 2 \mathrm{e}$ $100 \mathrm{~m} 2$. S ou Pequeno corresponde a um estabelecimento pequeno, que possui no máximo $20 \mathrm{~m} 2$. Associada a esta categoria, há uma outra: Sh que corresponde a um Conjunto de Casas Pequenas.

Ainda entre os Aspectos encontram-se duas categorias que dizem respeito ao material e ás técnicas de construção: $\mathbf{B}$ que corresponde a construções feitas com tijolo e/ou pedra, geralmente os dois materiais combinados; e $\mathbf{W}$ que corresponde a construções de madeira. É corriqueiro encontrar nos artigos ou relatórios sobre os assentamentos a associação, por um lado, das construções em tijolo e pedra a um estilo romano, e por outro, às de madeira a estilos de construção nativo (se no período romano inicial) ou bárbaro (se no período romano tardio). Aqui estou associando tais materiais a níveis de riqueza e ao grau de divisão social do trabalho que o processo de construção deste ou daquele estilo pressupõe. Neste sentido, por maior e mais elaborada que seja uma casa de madeira, e há poucas grandes casas de madeira entre os assentamentos listados, o número de funções especializadas que ela demanda para a sua construção é muito 
menor do que a construção de uma villa, ou mesmo de uma casa média que busca reproduzir em miniatura os equipamentos de uma villa.

Por fim, há os Aspectos que se referem aos elementos arquitetônicos cujo caráter aponta para dimensões funcionais do estabelecimento. $\mathbf{P}$ ou plantações indica a presença reconhecível de padrões de plantações antigas. Ar indica a presença de um altar grande ou pequeno, mesmo quando se trata de apenas uma hipótese não confirmada. BzWs corresponde a uma oficina de bronze, item que apresenta apenas uma ocorrência dentre os 60 estabelecimentos.

O segundo conjunto de categorias que corresponde ao segundo momento da análise se refere aos objetos encontrados nos assentamentos, cuja relação com as construções pode ser entendida como arbitrária, embora obedeça à lógica das relações sociais e ao comportamento cotidiano de seus habitantes. $\mathrm{O}$ segundo momento de análise, por sua vez, buscou delinear a evolução no tempo da distribuição dos objetos encontrados.

Há duas categorias para a cerâmica seriada encontrada nos assentamentos. F ou cerâmica fina, cujo processo de produção é mais complexo e cujo mapa de distribuição é maior, indicando circuitos regionais ou mesmo inter-regionais de distribuição. $\mathrm{C}$ ou cerâmica rustica indica uma produção menos elaborada, sem decoração e com distribuição mais localizada. A diferença aqui entre cerâmica fina e rústica não deve ser exagerada, já que a maior parte de ambos tipos de cerâmica encontradas até o século VI foi produzida de forma seriada. No contexto aqui analisado, a diferença na produção também responde a diferentes tipos de equipamento, de forma que é recorrente que se encontre ambos tipos de cerâmica no mesmo assentamento, assim como aos diferentes padrões de vida que se busca estudar aqui, uma vez que a cerâmica rústica era provavelmente de mais fácil aquisição, correspondendo a assentamentos mais simples.

Também há duas categorias que correspondem à presença de moedas nos assentamentos: SG para moedas de prata e ouro e Cp para moedas de cobre. Aqui também as duas categorias indicam padrões de vida e, mais especificamente, níveis de consumo comercial. As moedas de prata e de ouro indicam valores pecuniários mais altos e uma maior concentração de riqueza, sendo encontradas geralmente nos estabelecimentos maiores e ocasionalmente nos médios. Ambas foram colocadas dentro da mesma categoria porque entre os séculos III e IV o Império passa de um padrão monetário cujos maiores valores são expressos em moedas de prata para um baseado nas de ouro ${ }^{11}$. Aqui a categoria SG expressa um nível superior de riqueza monetária em oposição ao nível inferior expresso em moedas de cobre, de menor valor. As moedas de cobre, por sinal, têm uma grande importância, uma vez que sua presença nos assentamentos parece ser o resultado de um processo de difusão de práticas monetárias entre as camadas rurais mais pobres a partir do século IV - note-se que, a exemplo do que se constata no resto da Gália e do Império tardios, não há ocorrências de moedas de cobre nos assentamentos para períodos anteriores.

Por fim, há outras categorias de objetos encontrados. Alguns correspondem a maiores graus de divisão social do trabalho e especialização de funções, e outros a menores. No primeiro grupo estão I, objetos de ferro, Bz ou objetos de bronze, G, objetos de vidro, assim como uma categoria na qual estão subsumidas todas as técnicas associadas à decoração de uma villa construída com pedras e tijolos: BD ou decoração de villa/tijolos. No segundo grupo estão Fo, ou restos de comida 
(geralmente ossos de animais ou restos de grãos), Bu, ou enterramentos, e por fim Hf, o notório chão de cabana ${ }^{12}$.

Nas figuras 1 a 4 é possível ver o tratamento nos dados para o conjunto de todos os assentamentos da Lugdunense. Começando pela observação da distribuição dos aspectos de construção, o primeiro momento na análise, pode-se ver na Figura 1 que no período inicial há o predomínio de estabelecimentos de tipo villa (30 do total de 60). Mas isso não quer dizer que não haja estabelecimentos dos outros tipos. Há 12 estabelecimentos médios ( 11 de tijolo e pedra e 1 de madeira) e sete pequenos ( 6 de tijolo e pedra e 1 de madeira) e a ocorrência de um conjunto de casas de tijolo e pedra, que corresponde à Lugdunense IV. Há, ainda neste recorte, 10 assentamentos desocupados, um dado significativo, pois significa que um sexto do total de assentamentos estava vazio no período inicial.

Figura 1 - Aspectos período inicial - Lugdunense total

\section{Aspectos período inicial -}

\section{Lugdunense}

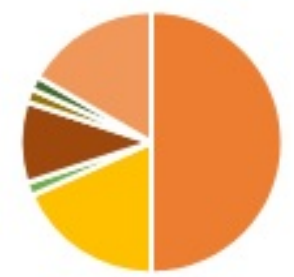

- VB = MB -SW -SB - MW -ShB =Empty

Figura 2- aspectos período tardio - Lugdunense total

\section{Aspectos período tardio - Lugdunensis}

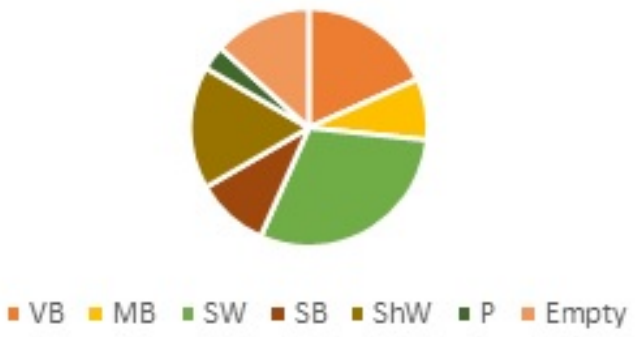

No período tardio, apresentado na Figura 2, tem-se o predomínio de ocorrências de estabelecimentos pequenos ( 34 no total, 6 de tijolo e pedra, 18 isoladas de madeira e 10 de madeira que aparecem em conjuntos). O número de estabelecimentos médios de tijolo e pedra aqui é de 5, menos de 10\%. Algo digno de atenção no que diz respeito a estabelecimentos médios é que há apenas uma ocorrência de estabelecimento médio, $\mathbf{M W}$, e somente no período inicial no total de 60 assentamentos. O número de estabelecimentos de tipo villa é apenas 
11, ou seja, um pouco menos do que um terço do conjunto de ocorrências de estabelecimentos pequenos.

A transição dos estabelecimentos grandes para pequenos fica evidente na Figura 3. Deve-se notar que, embora o uso da madeira em construções se dissemine, ainda há muito uso de pedra e tijolo.

Figura 3 - Variação de tamanho de casas - Lugdunense total

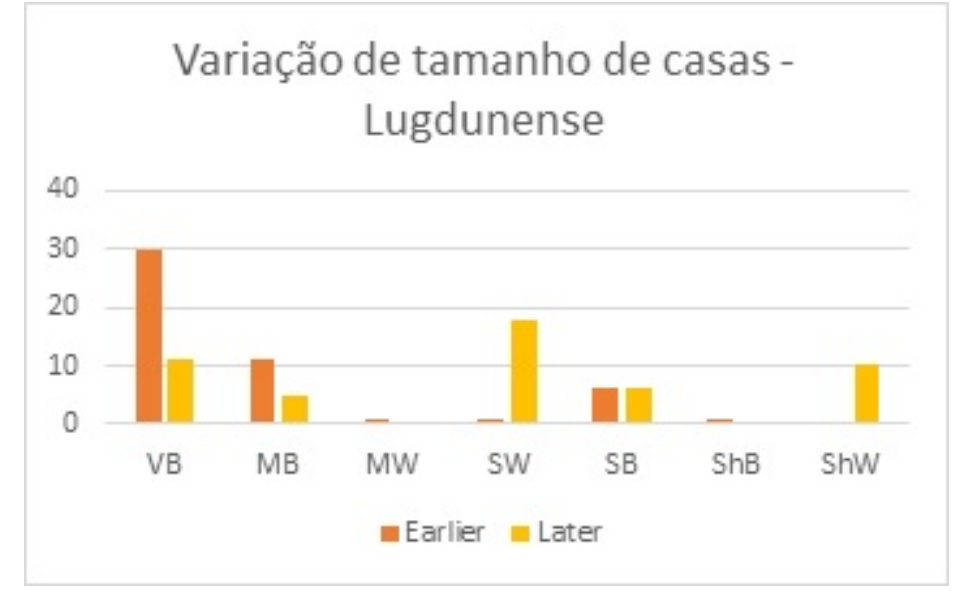

Figura 4 - Riqueza e ou Estilo - Lugdunense total

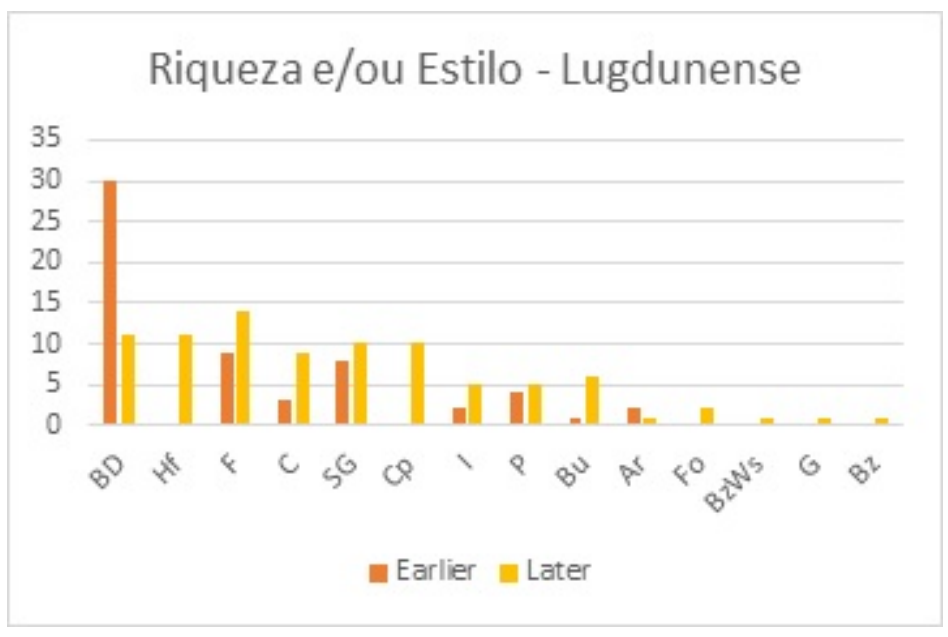

$\mathrm{Na}$ Figura 4 está apresentada a síntese dos achados de objetos nos assentamentos. A queda na presença de objetos ligados à decoração de villa é o que se destaca inicialmente. Mas é importante notar a maior profusão de objetos e encontrados em contexto rural no período tardio. Cerâmica fina e rustica, moedas de prata, ouro e cobre, objetos de ferro, de vidro, de bronze (e, claro, os chãos de cabana) aparecem em maior quantidade no período tardio, o que suportaria a hipótese de aumento de acesso dos habitantes rurais a estes itens entre os séculos III e VI.

\section{a4. Integração}

Neste último item apresento o tratamento dos dados que teve como objetivo criar representações possíveis dos processos de integração social nas regiões rurais 
analisadas. Isto quer dizer que o que se segue não é uma representação dos processos de integração como se deram, mas modelos teóricos formulados a partir dos dados recolhidos nos 60 assentamentos (Goodchild, 2013). Estes modelos, porém, são hipóteses plausíveis dos processos de interação das comunidades rurais com o seu entorno e com estruturas econômicas e políticas de maior amplitude associadas ao Império. Classifiquei tais estruturas aqui inspirando-me em Chris Wickham - em termos de sua amplitude: local, regional ou inter-regionais (Wickham, 2005). Abaixo será explicado como tais níveis se traduzem nas categorias que usei para montar os modelos.

Ainda, no que diz respeito à forma de construção dos modelos, é importante ter em mente que os pressupostos e critérios por trás do processo de categorização dos dados tem grande influência sobre os resultados apresentados. Contudo, isso não significa que o exercício de análise dos dados está condenado à tautologia, mas sim que é necessário garantir a clareza na apresentação dos pressupostos e critérios, assim como uma disposição crítica com relação aos resultados.

O principal pressuposto teórico do qual dependem os modelos de integração aqui apresentados é a quantidade de divisão social de trabalho e especialização que se pode inferir de diferentes tipos de objetos (Erdkamp, 2015). Quanto mais especializado for o tipo de produção por trás dos objetos encontrados nos assentamentos e, portanto, quanto mais complexo seu processo de produção e distribuição (não necessariamente comercial), maior o grau de integração social da qual eles podem ser representativos (Ward-Perkins, 2005; Wickham, 2005).

Esse pressuposto se traduziu em três categorias que representam três graus de maior ou menor integração social. Primeiro para o período imperial inicial e em seguida para o período tardio, cada um dos 60 assentamentos listados foi incluído em uma das categorias, dependendo do tipo de estabelecimentos e objetos ali encontrados. As três categorias de objetos que representariam os três níveis de integração social que eu proponho são N (ou Nível Baixo), L (ou Nível Local) e R (ou Nível Regional). Eu optei por não criar uma categoria que representasse a integração inter-regional porque ela criaria muitas dificuldades conceituais (uma discussão pantanosa se abriria sobre se as villa caberiam ou não nesta categoria; esta categoria incluiria as moedas cuja cunhagem era controlada imperialmente?) que não seriam compensadas nos modelos resultantes.

$\mathrm{Na}$ categoria que corresponde ao Nível Baixo se incluem estabelecimentos pequenos e médios de madeira, restos de comida e plantaçóes.

Na de Nível Local estão incluídos conjuntos de estabelecimentos de madeira ou de pedra e tijolo, estabelecimentos isolados pequenos ou médios de pedra e tijolo, cerâmica rústica, objetos de ferro, objetos de vidro, e os altares.

E por fim, na de Nível Regional estão incluídas as produções associadas às villae, cerâmica fina, achados de moedas (prata, ouro e cobre) e objetos de bronze (assim como a ocorrência solitária da oficina de bronze.

Ao observar como os objetos encontrados nos assentamentos poderiam ser incluídos nesta ou naquela categoria, também se levou em consideração como uma maior ou menor abrangência do que seria considerado mais ou menos integrado também teria implicações no dinamismo social representado pelo modelo resultante. Por causa disso, optei por categorias mais abrangentes. Assim, se por um lado, talvez tenha pecado ao seguir a bibliografia tradicional e valorizado bastante as produções associadas às villae como indício de maior 
integração social, por outro, também foram valorizados os objetos de produção seriada e elaborada. O resultado, ao contrário do que eu esperava, não foi uma visão mais estática do processo de integração apresentado nos dois períodos, mas a manutenção da tendência de queda da integração social entre os períodos inicial e tardio na Lugdunense.

$\mathrm{Na}$ Figura 5, encontra-se a representação dos níveis de integração para as quatro províncias Lugdunenses feita a partir dos dados de todos os assentamentos. No período inicial há uma alta integração regional (34), uma razoável integração local (15), mas o nível de baixa integração também não é pequeno (11). No período tardio, os assentamentos que contam como regionalmente integrados caem (21), e os que apresentam baixa integração sobem até ficar em mesmo número. Os localmente integrados, por sua vez, aumentam um pouco. Partindo destes resultados, o grau de integração social das áreas rurais da Lugdunense cai, se observarmos do ponto de vista regional, mas há um aumento importante das conexões que chamei de locais. Nesse quadro final há uma forte influência do maior número de assentamentos da Lugdunense IV, cuja representação isolada apresenta uma grande manutenção da integração (local e regional). Tal manutenção, porém, não reflete um estatuto privilegiado da região no período; pelo contrário, a Lugdunense IV é considerada uma região econômica e politicamente periférica se comparada com a Lugdunense I. Esta região é a mais extensivamente investigada - daí minha maior facilidade em encontrar os estudos sobre os assentamentos rurais relativos a ela - e por isso o seu impacto no quadro final deve ser interpretado como uma tendência que equilibra a representação da evolução dos processos de integração da Lugdunense entre o período inicial e tardio.

Figura 5 - Níveis de Integração - Lugdunense Total

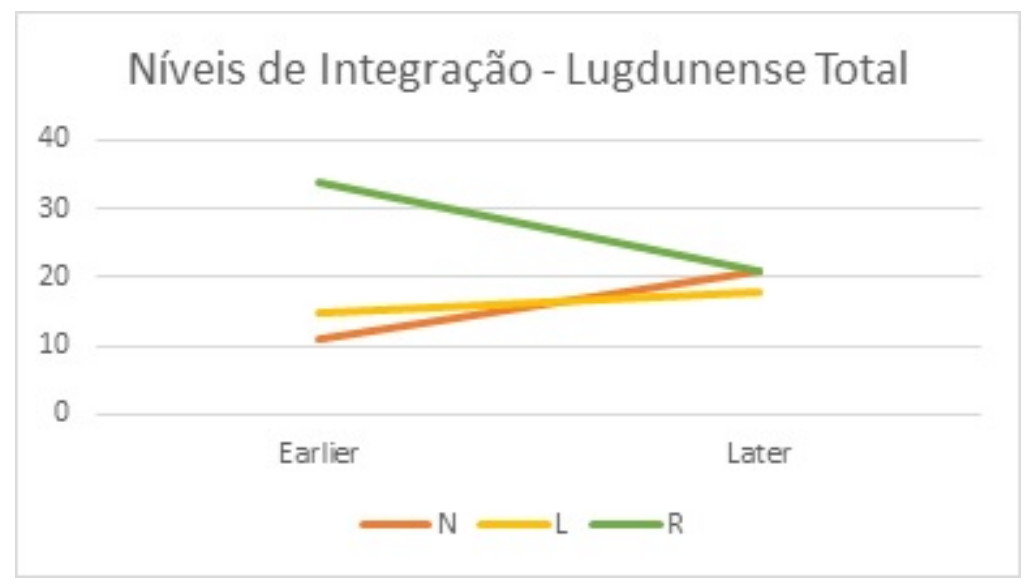

\section{Conclusão - Modelos e Conceitos de Comunidades Rurais}

A análise dos dados que se viu nas páginas anteriores parece dar razão para interpretações que atenuam a violência do impacto da crise do século III na Gália romana, ou, pelo menos na Lugdunense. Pois, se inicialmente verifica-se que de fato há rupturas no século III, elas são pequenas em comparação com as visões tradicionais de "Queda e Decadência do Império Romano" e são seguidas por retomadas significativa das atividades no século IV. Assim, há uma queda da 
ocupação dos assentamentos rurais no III, mas uma recuperação no IV (com a queda do século $\mathrm{V}$ parecendo ser muito mais significativa). Da mesma forma, ao menos nos dados recolhidos por prospecção na Île-de-France, a teorias de nucleação no período tardo-romano proposta por Wightman não se confirma. No que diz respeito às ideias de empobrecimento ou piora das condições sociais dos habitantes das regiões rurais, a análise aqui apresentada novamente tende a se distanciar da visão consensual no século XX que afirmava uma piora intensa das condições de vida. A queda do número de grandes casas rurais, assim como das atividades ligadas aos processos de construção e decoração poderia confirmar o cenário de empobrecimento e perda de integração. No entanto, a julgar pelos indícios de padrão de vida que se disseminam nas áreas rurais no período tardio - acesso a cerâmica seriada, moedas e outro objetos, pela presença e em certos casos crescimento do número de residências médias, assim como pelo aumento do nível local de integração - parece que a visão anterior de comunidades rurais miseráveis dominadas por potentados rurais não é sustentável.

As comunidades rurais que podem ser inferidas da análise e dos modelos propostos aqui estão inseridas em um quadro social mais complexo e dinâmico do que a sociedade Galo-romana dividida apenas em dois polos: um campesinato semi-escravizado e aristocratas gradualmente se tornando senhores da guerra locais. Ao menos até o início do século V, o que se encontra na cultura material das regióes rurais da Lugdunense são sinais de práticas sociais- econômicas e culturais - que apresentam múltiplos níveis de interação e mobilidade social.

Estas são as dimensões visíveis na documentação arqueológica aqui analisada. A grande questão que resta, contudo é a que diz respeito àquilo que estou chamando de dimensões invisíveis. Pois, embora as dimensões visíveis sejam adequadas para delinear alguns dos desenvolvimentos sócias que ocorrem nas regiões estudadas, elas não bastam para que se encontre as comunidades rurais que são o objetivo principal da pesquisa aqui apresentada. As análises aqui apresentadas e os modelos de integração propostos servem para a elaboração de um contexto social geral no qual estariam inseridas as comunidades rurais. E, neste sentido, mesmo a análise arqueológica de casos particulares de assentamentos rurais raramente é suficiente para chegar a uma compreensão das relações sociais e políticas das comunidades rurais antigas. Alguns dos modelos aqui propostos, como a variação dos níveis de riqueza (ou mudança de estilos de consumo) local, assim como a variação do índice de integração local, neste sentido, podem servir de sinal aproximado do que se passava nessas comunidades, isto é, representar em alguma medida as relações econômicas e sociais entre as comunidades rurais ou dentro delas comunidades.

No entanto, as formas nas quais se dão e o delineamento mais concreto daqueles múltiplos níveis de interação e mobilidade social dependem daquilo que denominei dimensões invisíveis, cuja compreensão depende em larga medida da documentação escrita e da imaginação sociológica, antropológica e histórica. É forçoso afirmar a necessidade da elaboração de modelos e categorias que descrevem e explicam as estruturas e fronteiras internas e externas dessas comunidades rurais e as suas formas de organização comunitária, que parecem ter se dado em termos muito mais complexos e dialéticos do que se postulava na historiografia do século XX. 
Ainda assim, muitos são os limites impostos pela evidência disponível para o estudo das comunidades rurais tardo antigas. Pode-se argumentar com certa convicção que boa parte das relações sociais fundamentais que durante muito tempo a historiografia atribuiu a estas comunidades são invisíveis mesmo na documentação escrita.

Eu não iria tão longe na argumentação da invisibilidade dessas relações. Acredito, porém, que se deva ter muito mais cuidado com as generalizações que se faz a partir de um conjunto localizado de documentos escritos. O objetivo dos historiadores que observam as áreas rurais antigas ou tardo-antigas é, em última instância, propor modelos ou representações das formas com as quais as relações sociais, econômicas e políticas se davam. Isto é, criar representações, plausíveis e controláveis pela evidência, das formas de trabalho (considerando as diferenças entre escravidão e trabalho livre, onde o debate sobre colonato desempenha um papel decisivo), das estruturas de patronato rural (em sua grande variedade), da propriedade da terra (e seus desdobramentos em termos de posse condicionada), assim como das formas de domínio político dos habitantes das comunidades. Neste contexto, o que observei aqui como padróes de integração pode servir como uma aproximação da interação interna e externa dessas comunidades, permitindo-nos refletir sobre as relações de interdependência e os processos dialéticos de enriquecimento e empobrecimento nas comunidades como algo associado aos níveis cada vez maiores de integração social. Um elemento importante destes modelos é que é possível inferir reciprocamente e dedutivamente os graus de exploração do trabalho rural e da concentração de riqueza a ela associada.

Uma consequência dessa forma de observar as comunidades rurais é que isso pode permitir observar um objeto que geralmente é ignorado ou menosprezado, geralmente com a justificação de que é invisível na documentação: a organização política das comunidades. A verdade é que ela é tão invisível quanto, digamos, a propriedade da terra, que tem páginas e mais páginas especulativas escritas a seu respeito. Para concluir e, levando em consideração a representação da sociedade tardo-romana no Norte da Gália esboçada neste artigo (a saber, uma sociedade muito mais complexa, dinâmica do que se pensava, e que, ainda que tenha polos de classes sociais bem definidos, havia muita interação social acontecendo entre os polos), acredito ser possível a partir dessa perspectiva criar modelos para a organização política dessas comunidades. Modelos que lidem ao mesmo tempo com as relações de poder e exploração oriundas do centro provincial e dos grandes proprietários locais e regionais, quanto com a organização própria dos habitantes das comunidades rurais que não pode ser compreendida em separado da observação da melhora ou da piora dos seus padrões de vida dos e das relações que estabelecem fora das comunidades onde vivem.

\section{Referências}

Agache, R. (1970). Detéction Aérienne des Vestiges Protohistoriques, Gallo-Romaines et Médiévaux dans le Basin de la Somme et ses Abords. Amiens: Musee de Picardie.

Agache, R. (1978). La Somme pré-romaine et romaine d'aprés les prospection aériennes à basse altitude. Amiens: Société des Antiquaires de Picardie. 
Alcock, S. E. (1996). Graecia Capta: The Landscapes of Roman Greece. Cambridge University Press.

Alcock, S. E. (2000). Extracting meaning form poughsoil assemblages: Assesments of the past, strategies for the future. In R. Francovich, H. Patterson, \& G. Barker (Orgs.), Extracting meaning from ploughsoil assemblages (p. 1-4). Oxford: Oxbow.

Anderson, P. (2000). Passagens da Antiguidade ao Feudalismo. São Paulo: Brasiliense.

Aston, M., \& Rowley, T. (1974). Landscape archaeology: An introduction to fieldwork techniques on post-Roman landscapes. Newton Abbot: David \& Charles.

Banaji, J. (2007). Agrarian Change in Late Antiquity. Gold, Labour, and Aristocratic Dominance. Oxford: Oxford University.

Banaji, J. (2010). Theory and History: Essays on Modes of Production and Exploitation. Leiden: Brill.

Banning, E. B. (2002). Archaeological survey. New York: Kluwer Academic/Plenum Publishers.

Barker, G. (1991). Approaches to archaeological Survey. In G. Barker \& J. A. Lloyd (Orgs.), Roman landscapes: Archaeological survey in the Mediterranean region ( $\mathrm{p}$. 1-9). London: British School at Rome.

Becker, J. A., \& Terrenato, N. (2012). Roman Republican Villas: Architecture, Context, and Ideology. University of Michigan Press.

Bernstein, Henry., \& Byres, T. J. (2001). From Peasant Studies to Agrarian Change. Journal of Agrarian Change, I, 1-56.

Bowden, W., Lavan, L., \& Machado, C. (2004). Recent Research on the Late Antique Countryside. BRILL.

Bowersock, G.V. Brown, P., Grabar, O. (2001). Interpreting Late antiquity: Essays on the post classical world. Cambridge: Belknap.

Bowman, A., \& Wilson, A. (2013a). Introduction: Quantifying Roman Agriculture. In The Roman Agricultural Economy. Organization, investment and production (p. 132). Oxford: Oxford University.

Bowman, A., \& Wilson, A. (Orgs.). (2013b). The Roman Agricultural Economy. Organization, investment and production. Oxford: Oxford University.

Brown, Peter. (1971). The World of Late Antiquity. London: Routledge.

Cameron, A. (1993). The Mediterranean World in Late Antiquity: AD 395-700. London: Routledge.

Carandini, A. (Org.). (1985). Settefinestre. Una Villa Schiavistica Nell'Etruria Romana. Vol. 1 La Villa nel suo Insieme. (Vol. 1). Modena: Panini.

Cardoso, C. F. S. (2002). Camponês, campesinato: Questóes acadêmicas, questões políticas. In A. Leonardo. Chevitarese (Org.), O Campesinato na História (p. 1938). Rio de Janeiro: Relume Dumará.

Carrié, J.-M. (1983). Un roman des origines: Les généalogies du "'colonat du BasEmpire". Opus, 205-251.

Carrié, J.-M. (1994). Dioclétien et la fiscalité. Antiquité Tardive, 2, 33-64.

Carrié, J.-M. (1997). “Colonato del Basso Impero” la resistenza del mito. In E. Lo Cascio (Org.), Terre, proprietari e contadidni dello impero romano (p. 75-150). Roma: La nuova Italia Scientifica.

Carrié, J.-M., \& Rousselle, A. (1999). L’Empire romain mutation: Des Sévéres à Constantin, 192-337. Paris: Éd. du Seuil.

Carrié, J.-Michel. (1982). Le “'colonat du Bas-Empire”': Un Mythe Historiographique? Opus, 351-371. 
Chavarría, A., \& Lewit, Tamara. (2004). Archaeological research on late antique countryside: A bibliographical essay. In W. Bowden, L. Lavan, \& C. A. R. Machado (Orgs.), Recent Research on the late antiquity Countryside (p. 3-51). Leiden: Brill.

Chouquer, G., \& Favory, F. (1991). Les Paysages de l'Antiquité. Terres et cadastres del'Occident romain. Paris: Errance.

Colleyn, J.-P. (1983). Du concept de communauté en anthropologie économique et sociale. In Communautés rurales (Vol. 1, p. 23-33). Paris: Dessain et Tolrat.

Daveau, I. (1997). Occupation des sols Bas Empire en Île de France. Rupture et continuité: Trois études de cas. In P. Ouzoulias \& P. Van Ossel (Orgs.), Les campagnes de I'île de france de Constantin à Clovis. Colloque de Paris. Raports et synthèses de la Deuxième Journée. Document de travail, III (p. 22-30). Paris: CNRS.

David, B., \& Thomas, J. (2008). Handbook of Landscape Archaeology. Walnut Creek: Left Coast Press.

Davies, W., \& Astill, G. G. (1994). The East Brittany Survey: Fieldwork and Field Data. Aldershot: Scolar Press.

De Coulanges, F. (1894). Le colonat romain. In Recherches sur quelques problèmes d'histoire (p. 3-186). Paris: Hachette et cie.

Dossey, L. (2010). Peasant and Empire in Christian North Africa. Berkeley: University of California.

Dyson, S. L. (2003). The Roman countryside. London: Duckworth.

Erdkamp, P. (2015). Agriculture, Division of Labour, and the Paths to Economic Growth. In P. Erdkamp, K. Verboven, \& A. Zuiderhoek (Orgs.), Ownership and Exploitation of Land and Natural Resources in the Roman World (p. 19-39). Oxford: Oxford University Press.

Erdkamp, P., Verboven, K., \& Zuiderhoek, A. (2015). Ownership and Exploitation of Land and Natural Resources in the Roman World. Oxford: Oxford University Press.

Feinmann, G. M. (2015). Settlement and Landscape Archaeology. In International Encyclopedia of the Social \& Behavioral Sciences (2o ed, Vol. 21, p. 654-658). Oxford: Elsevier.

Ferdière, A. (1988a). Les Campagnes en Gaule Romaine. Tome 1. Les techiniques et les productions rurales en Gaule. Paris: Errance.

Ferdière, A. (1988b). Les Campagnes en Gaule Romaine. Tome 2. Les hommes et l'environnement en Gaule rurale. Paris: Errance.

Finley, M. I. (1999). Ancient Economy. Berkeley: University of California.

Garnsey, P. (2010). Roman Patronage. In S. McGill, C. Sogno, \& E. Watts (Orgs.), From the Tetrarchs to the Theodosians: Later Roman History and Culture 284-450. Yale Classical Studies 34 (p. 33-54). Cambridge: Cambridge University.

Gellner, E. (1997). Cultura, Limite e Comunidade. In Antropologia e Política. Revoluções no Bosque sagrado (p. 56-72). Rio de Janeiro: Zahar.

Giardina, A. (2007). The Transition to Late Antiquity. In Walter. Scheidel, Ian. Morris, \& Richard. Saller (Orgs.), The Cambridge Economic History of the Greco-Roman World (p. 741-768). Cambridge: Cambridge University.

Goffart, W. A. (2008). Salvian of Marseille, De Gubernatione Dei 5.38-45 and the "Colonate" Problem. Antiquité Tardive, 269-288. 
Goodchild, H. (2013). GIS Models of Roman Agricultural Production. In A. Bowman $\&$ A. Wilson (Orgs.), The Roman Agricultural Economy. Organization, investment and production (p. 55-84). Oxford: Oxford University.

Grey, C. (2011). Constructing Communities in the Late Roman Countryside. Cambridge: Cambridge University.

Halstead, P. (1987). Traditional and Ancient Rural Economy in Mediterranean Europe: Plus ça Change. the Journal of Hellenistic Studies, 77-87.

Horden, P., \& Purcell, N. (2000). The Corrupting Sea. A study of Mediterranean History. Oxford: Blackwell.

Jullian, C. (1926). Histoire de la Gaule. Paris: Hachette.

Krause, J.-U. (1987). Spätantike Patronatsformen im Westen des Römischen Reiches. München: C.H. Beck.

Lambert, D. (2002). History and community in the works of Salvian of Marseille. Thesis DPhil--University of Oxford, Oxford.

Lefebvre, H. (1978). Problemas de sociologia rural. La comunidade rural y sus problemas historicos-sociológicos. In De lo rural a lo urbano (p. 19-38). Barcelona: Península.

Lenz, K. H. (2001). Late Roman rural settlement in the southern part of the province Germania Secunda in comparison with other regions of the Roman Rhineland. In P. Ouzolias, C. Pelleucer, C. Raynaud, P. Van Ossel, \& P. Garmy (Orgs.), Les campagnes de la Gaule à la fin de l'antiquité (p. 113-146). Antibes: APDCA.

Leveau, P. (2007). The Western Provinces. In W. Scheidel, I. Morris, \& R. Saller (Orgs.), The Cambridge Economic History of the Greco-Roman World (p. 651670). Cambridge: Cambridge University.

Lewit, T. (1991). Agricultural Production in the Roman Economy, A.D. 200-400. Oxford: B.A.R.

Lot, F. (1989). La Fin du monde antique et le début du Moyen Âge. Albin Michel.

MacMullen, R. (1992). Enemies of the Roman Order. Treason, unrest and alienation in the Empire. London: Routledge.

MacMullen, R. (1987). Late Roman Slavery. Historia, 36(1), 359-382.

Marx, K. (2011). Grundrisse. São Paulo: Boitempo.

Mészáros, I. (2012). A Obra de Sartre. A busca da Liberdade e Dsafio da História. São Paulo: Boitempo.

Millet, M. (1991). Pottery: Population or supply patterns? The Ager Tarraconensis approach. In G. Barker \& J. A. Lloyd (Orgs.), Roman landscapes: Archaeological survey in the Mediterranean region (p. 18-26). London: British School at Rome.

Millet, M. (2000). Dating, quantifying and utilizing pottery assemblages from surface survey. In R. Francovich, H. Patterson, \& G. Barker (Orgs.), Extracting meaning from ploughsoil assemblages (p. 53-59). Oxford: Oxbow.

Ouzoulias, P. (2006). L'économie agraire de la Gaule: Aperçus historiographiques et perspectives archéologiques (Doctorat - Archéologie). Université de FrancheComté, Besançon.

Ouzoulias, P., Pelleucer, C., Raynaud, C., Van Ossel, P., \& Garmy, P. (Orgs.). (2001). Les campagnes de la Gaule à la fin de l'antiquité. Antibes: APDCA.

Ouzoulias, P., \& Van Ossel, P. (2009). Petites et grandes exploitations agricoles: Le cas de la Plaine de France. In P. Leveau, C. Raynaud, \& R. Sablayrolles (Orgs.), Les formes de l'habitat rural gallo-romain: Terminologies et typologies à l'épreuve des 
réalités archéologiques. Association d'étude du monde rural gallo-romain Colloque (8\#; 2007\#; Toulouse) (p. 111-121). Bourdeaux: Aquitania.

Ouzoulias, P., \& Van Ossel, P. (2000). Rural Settlement economy in northern Gaul in the Late Empire: An overview and assessment. Journal of Roman Archaeology, 13, 133-160.

Ouzoulias, P., \& Van Ossel, P. (2001). Dynamiques du Peuplement et formes de l'habitat tadif: Le cas de l'Ille-de-France. In P. Ouzolias, C. Pelleucer, C. Raynaud, P. Van Ossel, \& P. Garmy (Orgs.), Les campagnes de la Gaule à la fin de l'antiquité (p. 147-172). Antibes: APDCA.

Peytremann, E. (2003). Archéologie de l'habitat rural dans le nord de la France du IVe au XIIe siècle, (Mémoires de l'Association Française de l'Archéologie Mérovingienne XIII). Saint-Germain-en-Laye: AFAM.

Pirenne, H. (1970). Maomé e Carlos Magno. Lisboa: Dom Quixote.

Ploeg, J. D. V. der. (2008). The New Peasantries: Struggles for Autonomy and Sustainability in an Era of Empire and Globalization. London: Earthscan.

Rorison, M. (2001). Vici in Roman Gaul. Oxford: BAR-Archaeopress.

Sartre, J.-Paul. (1973). Questão de método. In Satre. Ospensadores vol. XLV. São Paulo: Abril Cultural.

Scheidel, W., Morris, I, \& Saller, R. (Orgs.). (2007). The Cambridge Economic History of the Greco-Roman World. Cambridge: Cambridge University.

Ste. Croix, G. E. M. de. (1998). The class strugle in the Ancient Greek World. Ithaca: Cornell University.

Van Dam, R. (1985). Leadership and Community in Late Antique Gaul. Berkeley: University of California.

Van Ossel, P. (1992). Établissements ruraux de l'Antiquité tardive dans le nord de la Gaule, (51e Supplément à Gallia). Paris: Centre National de Recherche Scientifique.

Van Ossel, P. (2006). Rural Impoverishment in Northern Gaul at the End of Antiquity: The Contribution of Archaeology. In W. Bowden, L. Lavan, \& C. Machado (Orgs.), Social and Political Life in Late Antiquity (p. 534-565). Leiden: Brill.

Ward-Perkins, B. (2005). The Fall of Rome: And the end of civilization. Oxford: Oxford University.

Weber, M. (2013). The Agrarian Sociology Of Ancient Civilizations. London: Verso Books.

Weber, M. (1983). As causas sociais da decadência da cultura antiga. In G. Cohn (Org.), Weber (p. 37-57). São Paulo: Ática.

Whittaker, C. R. (1993a). Circe's Pigs: From Slavery to Serfdom in the Later Roman World. In C. R. Whittaker (Org.), Land, City and Trade in the Roman Empire (p. V, 89-120). Aldershot: Variorum-Ashgate.

Whittaker, C. R. (1993b). Rural labour in Three Roman Provinces. In Land, City and Trade in the Roman Empire (p. II 73-99). Aldershot: Variorum.

Wickham, C. (2005). Framing the Early Middle Ages. Europe and the Mediterranean 400-800. Oxford: Oxford University.

Wightman, E. M. (1978). Peasants and Potentates: An investigation of Social Structure and Land Tenure in Roman Gaul. AJAH, 3(2), 97-128.

Zuiderhoek, A. (2015). Land and Natural Resources in the Roman World in Historiographical and Theoretical Perspective. In P. Erdkamp, K. Verboven, \& A. 
Zuiderhoek (Orgs.), Ownership and Exploitation of Land and Natural Resources in the Roman World (p. 1-18). Oxford: Oxford University Press.

\section{Notas}

1 Atualmente é professor de História Antiga na Universidade Federal rural de Pernambuco- Campus Recife. Doutor em História Social pela Universidade de São Paulo com uma pesquisa sobre a escrita da História das classes subalternas e as revoltas rurais na África e na Gália do Império Romano tardio, período o qual foi bolsista da Fundação de Amparo à Pesquisa do Estado de São Paulo (Fapesp). Foi pesquisador em pós-doutoramento, entre 2015 e 2017, junto ao Departamento de História da Universidade de São Paulo com uma pesquisa sobre os assentamentos e a organização social dos camponeses na Gália tardo-romana, o que incluiu um estágio como pesquisador visitante na Universidade de Oxford, também com apoio da Fapesp. Membro do Laboratório de Estudos do Império Romano e Mediterrâneo Antigo da Universidade de São Paulo e da sessão Pré-capitalismo do Núcleo Interdisciplinar de Estudos e Pesquisas sobre Marx e o Marxismo.

2 Este artigo é o resultado de um período de estudos de pós-doutorado junto ao Departamento de História da Universidade de São Paulo e como Acadêmico Visitante em Oxford ambos com auxílio da Fundação de Amparo à Pesquisa do Estado de São Paulo. O trabalho aqui apresentado deve bastante ao diálogo com Norberto Luiz Guarinello e com Bryan Ward-Perkins, contudo, as eventuais limitações que o leitor possa encontrar aqui são de total responsabilidade do autor

3 O termo "Romanitas", proposto por Henri Pirenne (1970), se refere às regiões do Império Romano onde tal continuidade se desenvolveu, mesmo após a queda do Imperador em Roma.

4 Para uma síntese das questões, cf. Colleyn (1983) e também o ensaio de Ernst Gellner (1997) que emprega engenhosamente esses conceitos.

5 Eu parto da reflexão teórico metodológica realizada por Jean Paul Sartre (1973: 140) em Questão de Método, que, por sua vez, partiu de uma investigação especificamente sobre sociologia rural feita por Henri Lefebvre (1978). Para uma reflexão sobre os limites das propostas de Sartre e o lugar da mediação em sua visão de totalização dialética, cf. Mészáros (2012: 235-274).

6 A bibliografia é infindável, desde o tratamento inacabado mas rico de Marx (2011), ou as dicotomias engenhosas de Weber (2013), passando pela oposição canônica entre campo e cidade proposta por Moses Finley (1999), até o desafio mais recentemente lançado por Peregrine Horden e Nicholas Purcell na forma de "processos de ruralização" (2000).

7 Cf. a proposta de Horden e Purcell (2000: 271) de ignorar a noção.

8 São exemplos fundamentais dessa tendência Fustel De Coulanges (1894), Camille Julian (1926), Ramsay McMullen (1992, 1987), Van Dam (1985) e Whitaker (1993b, 1993a).

9 A historiografia recente desconstruiu vários dos pilares desse modelo de patronato rural de longa duração. Tanto por meio da reconsideração da força do patronato rural, quanto da interpretação da legislação sobre colonos como sendo a criação de uma forma de proto-servidão feudal (Carrié, 1983, 1997, 1982; Garnsey, 2010; Krause, 1987).

10 Embora haja hoje muitas pesquisas arqueológicas realizadas sobre o Norte da Gália, parte considerável dos resultados dessa pesquisa não foi publicada ainda, e muitas das informações sobre escavações ou prospecções só podem ser encontradas em catálogos ou relatórios de atividade com baixa tiragem, só encontrados nas bibliotecas de institutos arqueológicos regionais espalhados pela França.

11 Não pretendo adentrar aqui no delicado debate relativo a esta transição, muito menos nos meandros das teorias de uma hiperinflação no século III e IV e a sua revisão mais recente (Banaji, 2007; Carrié, 1994; Carrié \& Rousselle, 1999).

12 Pequenos edifícios de armazenamento (principalmente as chamadas sunken house ou Grubenhaus), que começam a aparecer na Gália setentrional a partir do século III. Anteriormente interpretadas como indícios da presença de povos bárbaros, uma vez 
que tal prática é encontrada em assentamentos além do Reno, mais recentemente passaram a ser interpretadas como de uma convergência técnica entre os povos bárbaros e as camadas rurais mais pobres (Ouzoulias \& Van Ossel, 2000: 149). 